\title{
A Study on the Path of Promoting Innovation Performance in Rural Areas under Organizational Inertial Environment
}

\author{
Xinjie Chen ${ }^{1, a}$, An Yang ${ }^{2, b}$, Zhen Li ${ }^{3, c}$, Xin Lan ${ }^{4, d *}$ \\ ${ }^{1-3}$ Sichuan University Jincheng College, sichuan, china \\ ${ }^{4}$ China West Normal University, sichuan, china; \\ Southwestern University of Finance and Economics, sichuan, china \\ a1144246867@qq.com, b32437945@qq.com, '7462177@qq.com, ${ }^{\mathrm{d}} 43717828 @ q q . c o m$ \\ *Corresponding author is Xin Lan
}

Keywords: Rural, Innovation performance, Organizational inertness, Ascension path

\begin{abstract}
Innovative creativity in rural areas is generally weak and lacks an active organizational atmosphere and environment. This paper focus on the influence of innovation performance in rural areas and their path of promotion on the background of organizational inertia. Through the field investigation of entrepreneurial enterprises in rural areas of Sichuan Province,the relationship between organizational inertia and innovation performance is obtained, and the path model of organizational innovation performance is proposed.
\end{abstract}

\section{Introduction}

In the time of internet+, Volkswagen entrepreneurial innovation and economic growth cause Rural entrepreneurial organizations are thriving which decrease the gap between rural areas and urban areas. However, it is caused the migrant workers innovation and creativity are weaker. Going through the past researches, we found that most researches are focus on entrepreneurial behavior, only a few researches focus on innovative behaviors and summary the causes of organizational environment. Organizational inertia is a resistance cannot be ignored and makes organizational change difficulty. Moreover, studies have shown that inertia, the features of organizational change, and the limit of change. Therefore, study on the organization's inertiais a good strategy to promote more change. Overcoming the shortcomings of previous studies by on-the-spot investigation, extract the correlation between the organizational inertia and innovation performance, and organizational innovation performance ascension path model is put forward.

\section{Hypothesis}

This study divides tissue inertia into structural inertia, strategic inertia, resource inertia and individual inertia, and puts forward the following research hypothesis model.

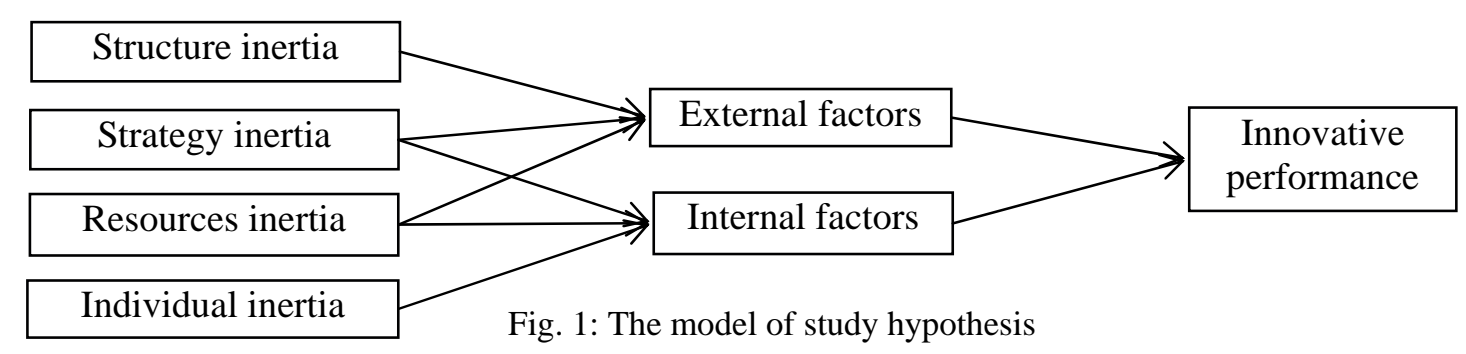




\subsection{Organizational structure inertia}

Hannan and Freeman, Staw, etc. suggested two inertia in the structural level, Firstly, information is restricted, which manifests as communication channel overload. Secondly, shrinkahe the control, which manifests as concentration of power, formalization and efficiency. In order to make the innovation between the cluster enterprises happen and to proceed smoothly, keeping the information unblocked between cluster enterprises become improtant. Klein and Rosenberg's chain-like innovation process model shows the feedback between the various links, the external environment and the ability of innovation enteprises to rcommunicate effectively on success of cluster innovation.Therefore, the following hypothesis is proposed:

H1a:Internal communication is positively correlated with the innovation performance.

H1b:External communication is positively correlated with innovation performance.

Leaders influence organizational innovation reflect on their responsibilities, resources integration and strategy. Leaders are the decision-makers in the organization who have the right to mobilize and integrate resources.If the leader can provide funds, personnel and other support, will promote the development of innovation.Egelhof suggests that if the formalization of organizational structure increases, companies will increase their restrictions on employees' behavior in formal documents and regulations, also can promote the trust in innovation.The formalized organizational structure enhances the confidence of innovators and builds an atmosphere of innovation. Therefore, the following assumptions are made:

H1c:Power concentration is positively related to innovation performance

H1d:Structural formalization and innovation performance are positively correlated

\subsection{Organizational strategy inertia}

Research suggests that motivation has an important role in the creation of innovative ideas and the implementation of innovative behavior, which are related to stress. The external motive is formed by external factors (eg. pressure, rewards and punishment, etc).Market competition has a positive effect on innovation:First,in the fierce competition environment, enterprises are facing the possibility of being eliminated.Enterprises can achieve product differentiation or reduce costs by developing new products or new technologies, inoder to obtain more market demand.External competitive pressure can encourage enterprises to invest more in innovation. Therefore, the following assumptions are made:

H2a:Members' psychological stress is positively related to innovation performance

H2b:Market competition pressure is positively related to innovation performance

The cultural atmosphere of the organization is very significant for the effect of organizational innovation. Ajzen and Fishbein found that individual behavior was influenced by the organizational culture. Employees are motivated to innovate if they arefair, friendly, innovative organization culture.Organizational innovation atmosphere can provide environmental support and psychological support for organizational innovation activities, and form a driving force to promote the generation of innovative behaviors.Secondly, under the influence of organizational innovation atmosphere, employees can participate in various innovation activities better.Therefore, the following assumptions are made:

H2c: Innovation atmosphere is positively related to innovation performance

\subsection{Organizational resources inertia}

Graham Matthews, from the perspective of resource support, analyzes how to make up the production gap by promoting farmers' technological innovation, and proves the importance of material resources to farmers' innovation.Granovetter think that strong links can enhance mutual trust and the development of companies. In recent years, many scholars have studied the relationship between relationship embedding and innovation performance. Relationship embedding 
can be seen as a unique resource owned by the company and it can promote resource sharing and thus promote enterprise cooperation.In addition, Venture capital institutions have a strategic role in the survival and development of small and medium-sized high-tech enterprises,overcome the complexity of innovation environment and technology, To enhance the efficiency of innovation.The knowledge and technology resources owned by enterprises are the important foundation to improve their innovative performance.applying collaboration and knowledge creation techniques can make the organization's work more effective. Therefore, the following assumptions are made:

H3a:The social network is positively correlated with innovation performance

H3b:Government agency support is positively correlated with innovation performance

H3c:Investment institutions is positively related to innovation performance

H3d:Organizational knowledge and technology are positively related to innovation

\subsection{Organizational individual inertia}

McCrae and Costa argue that individuals with open features are able to absorb new knowledge more quickly and to combine new and special information that is learned from the actual situation. Sternberg's investment theory formulated people with ability to judge and identify effectively can found the potential problems, also the motive can help people stimulate creativity, create creative ideas, Thus overcoming the problems encountered. Organizational members' creativity can greatly contribute to organizational innovation. Guilford published "creative" speech and suggested knowledge workers' creative personality has a positive predictive effect on individual innovation performance.Baron, Tang sees the new enterprise as the research object and finds that the creativity of entrepreneurs can promote the innovation performance of the organization.Therefore, the following assumptions are made:

H4a:Personality of members is positively related to innovation performance

H4b:Members' target motivations are positively related to innovation performance

H4c:The conformity psychology and inertial thinking of the members are negatively correlated with the innovation performance

H4d:Members' creativity is positively related to innovation performance

\subsection{The role of policy incentives (external factors)}

Freeman systematically studied the government as an intrinsic factor in technological innovation.Scholars of new institutionalism emphasize that the decisive role of the system in innovation fully demonstrates that reasonable institutional arrangements can promote innovation.Saul's data from Israel's manufacturing industry found that subsidies from the foreign trade and industry sectors could stimulate research and development spending by small businesses.the following hypothesis is proposed:

H5a:National strategic policy is positively correlated with innovation performance.

H5b:Local government's innovation subsidy is positively correlated with innovation

The venture park is equipped with a first-class innovative ecological environment to attract domestic and foreign innovation enterprises, research institutes to share opportunities in the park.Recently, zhengzhou city issued "the implementation opinions to support migrant workers return home entrepreneurship", by 2020, each county (city) to build $1 \sim 2$ migrant workers return home entrepreneurship park, highest can enjoy 400000 yuan one-time subsidies.Jiang jianwu pointed out that when the organization clarified the importance of innovation and offered special rewards, the incentive plan would connect employees' interests with creativity.Therefore, the following hypothesis is proposed:

H5c:The support of the venture park is positively correlated with the innovation.

H5d:Innovative reward system and innovation performance is positively related 


\subsection{The role of interest-driven (internal)}

The fundamental driving force behind the development of things is internal causes, and external causes are attached to internal causes. These may be for a raise, or for a promotion. The "demand induced innovation" theory proposed by Schmukler argues that the invention activity is basically the pursuit of profit economic activity, it is the market demand that has affected the technological innovation behavior.Mowery and Rosenberg further stressed that "innovation and market demand play an important role in the development of technology in an interactive manner".Therefore, the following hypothesis is proposed:

H6a: Job promotion is positively correlated with innovation performance

H6b:New market demand stimulus is positively related to innovation performance

H6c:Competitive advantage and innovation performance are positively correlated

\section{Empirical Research}

\subsection{Data collection}

We have $75.34 \%$ of our sample data from rural areas of sichuan. For comparison, we also collected some samples from other provinces.The distribution is as follows: chongqing 4.11\%, jiangsu $4.11 \%$, zhejiang $2.74 \%$, Shanghai $2.74 \%$, guangdong $2.74 \%$, hunan $2.74 \%$, hubei $1.37 \%$, tianjin $1.37 \%$.The respondents were the head of the project.From the questionnaire to the recycling questionnaire, it was about two months.A total of 500 questionnaires were issued, and 335 were actually obtained.In the actual recovered questionnaires, the effective questionnaires were 282 in rural areas.The survey questionnaire was divided evenly among provinces and industries, and selected representative samples in the industry,The samples are distributed in 6 industries,such as seedling,food processing,e-commerce,and agritainment.

\subsection{Variable definitions}

The structural equation model is an analytical model used to analyze the interactions between variables, and the variables involved are divided into explicit and latent variables from a measurable perspective. A dominant variable is a variable that can be observed and measured directly. A latent variable refers to a variable that cannot be directly observed and measured, but it can be characterized by a measure of the dominant variable. The potential variables of this research include seven factors, such as organizational structure inertness, organizational strategy inertness, organizational resource inertia, individual member inertia, external policy pull, internal interest promotion and innovation performance, and 26 observation variables, but due to limited space Not listed in detail, see Table 1. And lists the estimated values and significance of the observed variables (potential variable influencing factors).

\subsection{Analysis results and hypothetical tests}

The structural equation (SEM) used in this topic is a model to verify the mechanism of innovation impact. The structural equation is an analysis method which analyzes the data by multiple linear analysis, covariance analysis, path analysis and verification factor analysis The In this paper, we use AMOS 6.0 software to analyze the structural equations. The results are shown in Table 2.

From table 2, external policies to promote the innovation performance,inert structure and external policies, organization strategic inertia and external policies, resources of qualification inert and external policies promote the path coefficient respectively $(1.304,0.016,0.321$, 0.016) .CR,respectively (-4.996,0.176,1.333, 3.064) .

Significant level P except 0.86 and 0.183 were less than 0.05 , It shows that although external policies are significant to innovation performance,the path relationship is obvious,but the 
significance level of organizational strategy inertia and organizational resource inertia is less than 0.05.Indicating that there is no strong correlation between organizational inertia and innovation performance, assuming that 5 can't obtain empirical support.

Table 1 Factor reliability and validity test

\begin{tabular}{|c|c|c|c|}
\hline Potential variable & Influencing factor & Standardized estimates & C.R. \\
\hline \multirow{4}{*}{$\begin{array}{l}\text { Organizational } \\
\text { structure inertia }\end{array}$} & Internal open & 0.049 & 77.106 \\
\hline & External open & 0.051 & 76.31 \\
\hline & Power concentration & 0.054 & 71.271 \\
\hline & Formalized & 0.058 & 64.961 \\
\hline \multirow{4}{*}{$\begin{array}{l}\text { Organizational } \\
\text { strategy inertia }\end{array}$} & Psychological pressure & 0.066 & 48.293 \\
\hline & Competitive pressure & 0.062 & 55.955 \\
\hline & System rules & 0.054 & 72.853 \\
\hline & Innovative atmosphere & 0.064 & 50.514 \\
\hline \multirow{4}{*}{$\begin{array}{l}\text { Organizational } \\
\text { resources inactive }\end{array}$} & Social network & 0.056 & 68.387 \\
\hline & Government support & 0.048 & 77.03 \\
\hline & Financial support & 0.056 & 57.367 \\
\hline & Knowledg and technology & 0.052 & 75.64 \\
\hline \multirow{4}{*}{ Individual inertia } & Personality traits & 0.049 & 81.128 \\
\hline & Target and motive & 0.046 & 87.954 \\
\hline & A herd mentality & 0.071 & 41.973 \\
\hline & Creativity & 0.056 & 69.798 \\
\hline \multirow{4}{*}{$\begin{array}{c}\text { External } \\
\text { policy stimulates }\end{array}$} & National policy & 0.051 & 71.839 \\
\hline & Government subsidy & 0.052 & 71.402 \\
\hline & Venture park assistance & 0.056 & 60.931 \\
\hline & Sharing profit & 0.072 & 42.507 \\
\hline \multirow{4}{*}{$\begin{array}{l}\text { Internal } \\
\text { interest promotion }\end{array}$} & Job promotion & 0.071 & 40.79 \\
\hline & Market demand & 0.049 & 80.395 \\
\hline & Competitive advantage & 0.051 & 72.354 \\
\hline & Innovation quantity & 0.084 & 30.606 \\
\hline \multirow[t]{2}{*}{ Innovative performance } & Innovation quality & 0.051 & 34.391 \\
\hline & Business efficiency & 0.067 & 44.947 \\
\hline
\end{tabular}

The path coefficient of internal policy to innovation performance is 2.454 , the CR value is 4.905 , and the $\mathrm{P}$ value is less than 0.05 , which indicates that the internal policy of the enterprise has obvious positive correlation to the promotion of innovation. And the path coefficient of organizational structure inertia, organizational strategy inertia and organizational resource inertia are respectively $(0.458,1.81,0.993,0012)$, the CR values were $(3.595,2.573,2.309,0.194)$, The $P$ value is less than 0.05 except for the members, It is obvious that the impact of the organization's multi-line through the internal policy to the innovation performance is obvious, but the influence of the individual members on the performance of the enterprise is not obvious, no correlation. Hypothesis 4 cannot obtain empirical support.The trait coefficients of innovation performance to innovation quantity, innovation quality and enterprise benefit were $(1,0.656,0.763)$,CR values were (9.358,8.612), $\mathrm{P}$ values were less than 0.01 , sinusoidal positive correlation at 0.05 significance level relationship. It is shown that the proposed three variables can reflect the potential variables better.From other hypothesis, changing the organizational inertness of the internal policy to pull the correlation is more obvious, significant representation. This shows that the enterprise's ability to innovate there is a greater room for improvement. 
Table 2 Non-standard path coefficient table

\begin{tabular}{|c|c|c|c|c|c|c|}
\hline & Path & & $\begin{array}{c}\text { Nonstandard } \\
\text { Path coefficient }\end{array}$ & C.R. & $\mathrm{P}$ & $\begin{array}{l}\text { Degree } \\
\text { of support }\end{array}$ \\
\hline External policy & $<---$ & organizational structure & 0.016 & 0.176 & 0.86 & unsupported \\
\hline External policy & $<---$ & organizational strategy & 0.321 & 1.333 & 0.183 & unsupported \\
\hline External policy & $<---$ & organize resources & 3.101 & 3.064 & 0.002 & support \\
\hline Internal interest & $<---$ & organizational structure & 0.458 & 3.595 & $* * *$ & support \\
\hline Internal interest & $<---$ & organizational strategy & 1.81 & 2.573 & 0.01 & support \\
\hline Internal interest & $<---$ & organizational resources & 0.993 & 2.309 & 0.021 & support \\
\hline Internal interest & $<---$ & individual members & 0.012 & 0.194 & 0.846 & unsupported \\
\hline Innovative performance & $<---$ & external policy & 1.304 & -4.996 & $* * *$ & support \\
\hline Innovative performance & $<---$ & internal interest & 2.454 & 4.905 & $* * *$ & support \\
\hline Power concentration & $<--$ & organizational structure & 1 & & & \\
\hline External open & $<---$ & organizational structure & 1.153 & 5.095 & $* * *$ & support \\
\hline Internal open & $<---$ & organizational structure & 0.872 & 4.653 & $* * *$ & support \\
\hline Institutional rules & $<---$ & organizational strategy & 1 & & & support \\
\hline Competitive pressure & $<---$ & organizational strategy & 3.083 & 2.798 & 0.005 & support \\
\hline Psychological stress & $<---$ & organizational strategy & 2.182 & 2.601 & 0.009 & support \\
\hline Formalize & $<---$ & organizational structure & 1.012 & 4.59 & $* * *$ & support \\
\hline Innovative atmosphere & $<---$ & organizational strategy & 2.771 & 2.745 & 0.006 & support \\
\hline Innovative quantity & $<---$ & innovation performance & 1 & & & \\
\hline Innovation Quality & $<---$ & innovation performance & 0.656 & 9.358 & $* * *$ & support \\
\hline Enterprise efficiency & $<---$ & innovation performance & 0.763 & 8.612 & $* * *$ & support \\
\hline Knowledge technology & $<---$ & organizational resources & 1 & & & \\
\hline Financial support & $<---$ & organizational resources & 1.808 & 2.746 & 0.006 & support \\
\hline Government support & $<---$ & organizational resources & 2.881 & 3.058 & 0.002 & support \\
\hline Network resources & $<---$ & organizational resources & 1.405 & 2.519 & 0.012 & support \\
\hline Creativity & $<---$ & individual members & 1 & & & \\
\hline A herd mentality & $<---$ & individual members & 0.724 & 3.162 & 0.002 & support \\
\hline Target and motive & $<---$ & individual members & 1.451 & 5.309 & $* * *$ & support \\
\hline Personality traits & $<---$ & individual members & 1.357 & 5.601 & $* * *$ & support \\
\hline National policy & $<---$ & External policy & 1 & & & \\
\hline Benefit sharing & $<---$ & internal interest & 1 & & & \\
\hline Government subsidy & $<---$ & External policy & 1.126 & 9.203 & $* * *$ & support \\
\hline Job promotion & $<---$ & internal interest & 0.551 & 2.667 & 0.008 & support \\
\hline $\begin{array}{l}\text { Venture } \\
\text { park assistance }\end{array}$ & $<---$ & External policy & 1.024 & 8.278 & $* * *$ & support \\
\hline Market demand & $<---$ & internal interest & 0.636 & 3.832 & $* * *$ & support \\
\hline Competitive advantage & $<---$ & internal interest & 0.787 & 4.205 & $* * *$ & support \\
\hline
\end{tabular}

\section{Discussion of the Results}

Based on the theory of internal and external innovation, this paper makes the following conclusions through empirical analysis: Firstly, rural areas start-up enterprises through the organizational structure of the building and improvement, from the internal and external to promote enterprises to overcome the organizational structure of inertia, thus promoting innovation. Secondly, rural areas start-up enterprises through the development of corporate strategy, from the internal and 
external to promote enterprises to overcome the organizational strategy in the inertia, so as to promote innovation. Thidly, rural enterprises can through the integration of resources, the greatest use of external and internal resources to promote enterprises to overcome the inertia of organizational resources, thereby promoting innovation. Fourthly, rural enterprises can be through the enterprise staff training and recruitment, cultivate innovative talents adapting to enterprises,overcoming inertia from within the organization.

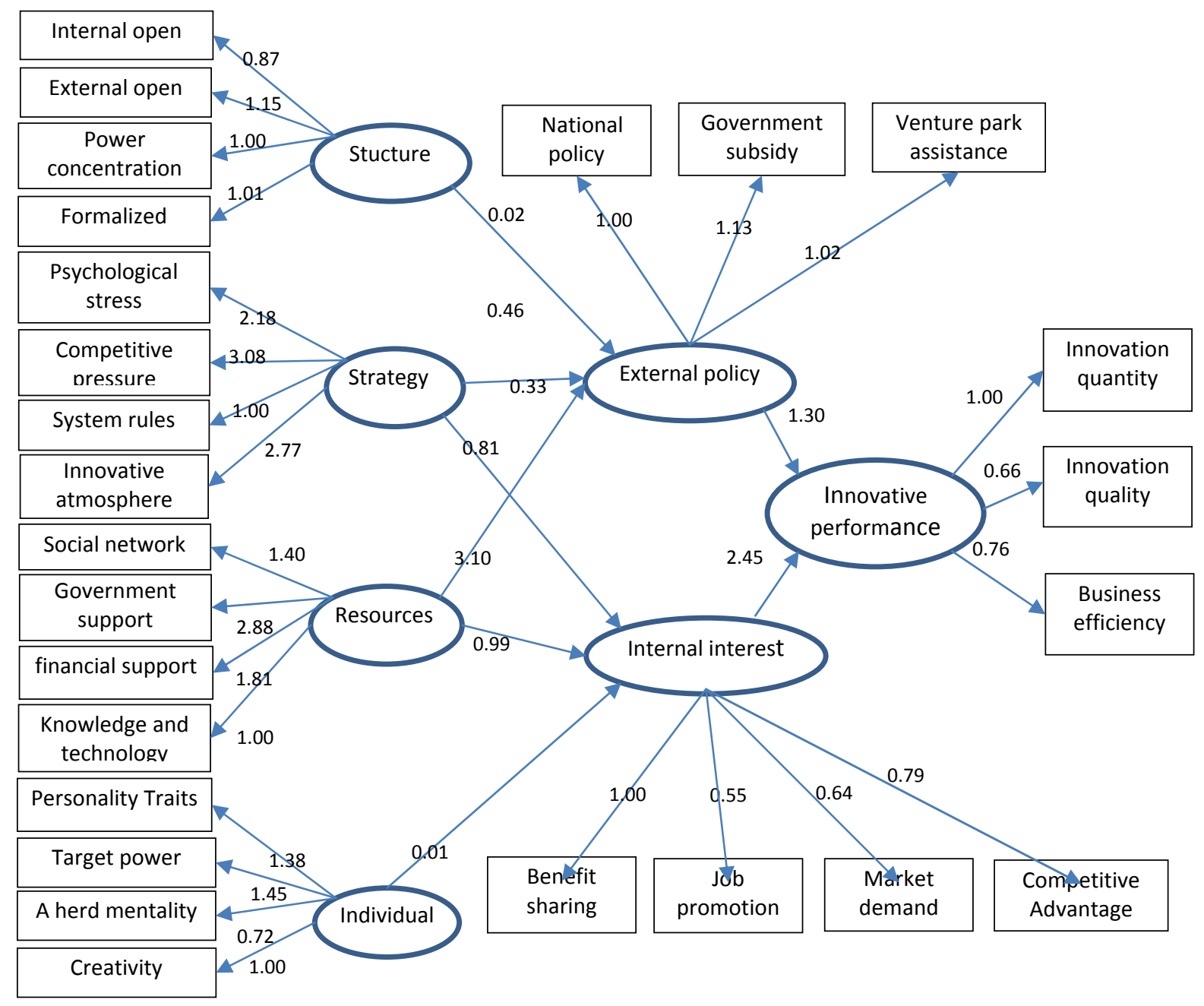

Fig. 2: the path model of organizational innovation performance

Finally, the internal driving force have four internal drivers of innovation in this paper. Firstly,enterprises should avoid nepotism to the greatest extent, establish a fair promotion can effectively motivate employees to innovate. Secondly, demand is the driving force of innovation. Enterprises should constantly conduct market demand survey and analysis, so as to find new market demand in time.Thirdly, the purpose of enterprise innovation is to gain competitive advantage, to gain differentiation advantage in market competition, and to improve the competitiveness of enterprises.Fourth, material incentives are one of the most effective incentives. For rural start-ups, material incentives are particularly important.In compensation incentive, widen innovation pay gap, through wage incentive innovation. The organization can build a profit sharing plan, which can bring organizations and employees together.This plan can not only reduce internal friction and retain talents, but also motivate employees and improve the efficiency of innovation, thus creating greater profits for enterprises. 


\section{Acknowledgement}

This paper is supported by the Sichuan Rural Development Research Center Project (provincial key research base of philosophy and social sciences, Project No.CR1611), Sichuan Agricultural Characteristic Brand Development and Communication Research Center Project (Ministry of Education, Humanities and Social Sciences Key Research Base, Project No. CAB1602), Sichuan Revolutionary Old Area Development Research Center project (provincial philosophy and social sciences, provincial education department humanities and social sciences research Base, Project No. SLQ2016B-07).

\section{References}

[1] Feldman,M. S. ,Pentland,B. T. Reconceptualizing Organizational Routines as a Source of Flexibility and Change[J].Administrative Science Quarterly,2003,48( 1) : 94-118.

[2] KlineSJ,RosenbergN. Anoverview of innovation[M].New York: National Academy Press, 1986.275-305.

[3] Daniel Kata,Robert Louis Kahn. The social pasychology of organization[M].New York:Wiley,1978:22-88.

[4] Nickell,S.J.,Competitionand corporate performance.Journal of political economy,Vlo 104,No.4,August 1996:724-746.

[5] Ajzen,I.\& Fishbein,M.Understanding attitudes and pre-dicting social behavior $[\mathrm{M}]$.Engle wood Cliffs,NJ: Prentice-Hall,1980.

[6] Transformation Leadership on Firm Innovation” [J].Leadership Quarterly,Vol.19.pp.582-594.

[7] Granovetter M S. Economic Action and Social Structure: The Problemof Social Embeddedness[J], American Journal of Sociology,1985,91( 3) : 481-510.

[8] Czarnitzki,D. and Licht,G.,2006,Additionality of Public R\&D Grants in a Transition Economy: The Case of Eastern Germany, Economics of Transition, Vol. 14, 1, pp:101-131.

[9] Sapienza H J,Amason A C,Manigart S.The level and nature of venture capitalist involvement in their portfoliocompanies: A study of three European countries[J].Managerial Finance,1994,20( 1) : 3-17.

[10]Robert J Sternberg. The Nature of Creativity [J].Creativity Research Journal, 2006, 18(1): 87-98

[11] Birkinshaw J,Hamel G,Mol M J. Management innova-tion[J].Academy of Management Review,2008,33( 4) : 825 -845.

[12] Alegre J,Chiva R. Assessing the impact of organization-al learning capability on product innovation performance:an empirical test[J].Technovation,2008,28( 6) : 315-326.

[13] Saul L.Do R\&D subsidies stimulate or displace private R\&D Evidence from Israel[J].Journal of IndustrialEconomics,2002,50( 4) : 369-390.

[14] Yang An . An empirical study on the Prisoners' Dilemma of management decision Using big data [C]. 10th ICMSEM 2016, The Engineering Index.

[15] Yang An . An empirical study on innovation and entrepreneurship education support system in the environment of big data [C]. 2016 ICSM, The CPCI-SSH Index.

[16] Yang An . Study on Countermeasures of Entrepreneurial Firms to Achieve Prediction and Position Using Big Data [C]. <ICCE2015>,June,2015, London, UK.27-28, The CPCI-SSH Index.

[17] Mahmood I P, Rufin C. Government's dilemma: The role of government in imitation and innovation [J].A-cademy of Management Review, 2005, 30( 2) : 338-360 